Gut and Liver, Vol. 10, No. 5, September 2016, pp. 706-713

\title{
Helicobacter pylori Eradication Therapy Is Effective as the Initial Treatment for Patients with H. pylori-Negative and Disseminated Gastric Mucosa-Associated Lymphoid Tissue Lymphoma
}

Eun Jeong Gong ${ }^{1}$, Ji Yong Ahn ${ }^{1}$, Hwoon-Yong Jung ${ }^{1}$, Hyungchul Park ${ }^{2}$, Young Bo Ko ${ }^{2}$, Hee Kyong Na ${ }^{1}$, Kee Wook Jung ${ }^{2}$, Do Hoon Kim ${ }^{1}$, Jeong Hoon Lee ${ }^{1}$, Kee Don Choi ${ }^{1}$, Ho June Song ${ }^{1}$, Gin Hyug Lee ${ }^{1}$, and Jin-Ho Kim ${ }^{1}$

Departments of ${ }^{1}$ Gastroenterology and ${ }^{2}$ Internal Medicine, Asan Medical Center, University of Ulsan College of Medicine, Seoul, Korea

See editorial on page 659.

Background/Aims: We investigated the effectiveness of Helicobacter pylori eradication therapy for gastric mucosaassociated lymphoid tissue (MALT) lymphoma regardless of the $H$. pylori infection status or disease stage. Methods: From November 1995 to September 2014, 345 subjects who were diagnosed with gastric MALT Iymphoma and had received eradication therapy as their first-line treatment were eligible for inclusion in this study. A retrospective review was performed using the medical records. Results: Of the 345 patients, $H$. pylori infection was detected in 317 patients (91.9\%). The complete remission (CR) rate after eradication therapy was $82.3 \%$, which was higher in $H$. pylori-positive patients than in $H$. pylori-negative patients $(84.5 \%$ vs $57.1 \%$, $p=0.001$ ). CR rates after eradication did not present significant differences between stages, and the CR rate was $83.3 \%$ for stage IE1 and $74.4 \%$ for stage IE2 or above ( $p=0.167$ ). The overall CR rate was $87.2 \%$ after additional treatment, and neither $H$. pylori infection status nor stage showed differences according to the treatment response. Conclusions: Eradication therapy led to $\mathrm{CR}$ in $57.1 \%$ of $\mathrm{H}$. pylori-negative patients and in $74.4 \%$ of patients with stage IE2 or above. Eradication therapy is worthwhile as an initial treatment for gastric MALT Iymphoma regardless of the $H$. pylori infection status and stage. (Gut Liver 2016;10:706-713)

Key Words: Helicobacter pylori; Mucosa-associated lymphoid tissue lymphoma; Remission

\section{INTRODUCTION}

Primary gastric marginal zone lymphoma of mucosa-associated lymphoid tissue (MALT) is a low-grade B-cell lymphoma with an indolent clinical course. Most gastric MALT lymphoma has been known to be associated with Helicobacter pylori infection, and $H$. pylori eradication therapy is regarded as the first-line treatment for patients with gastric MALT lymphoma confined to the gastric wall. ${ }^{1,2}$ Eradication of $H$. pylori induces complete histological remission in approximately $78 \%$ of gastric MALT lymphomas in early stage disease, and with a 5-year survival rate greater than $95 \%{ }^{3,4}$

Although the treatment strategy for $H$. pylori-positive MALT lymphoma is well established, the management for $H$. pylorinegative MALT lymphoma remains controversial. ${ }^{5,6}$ The complete remission (CR) rates for $H$. pylori-negative MALT lymphoma after $H$. pylori eradication therapy have been reported variously from $0 \%$ to $60 \%$, and the eradication therapy induced CR in 15.5\% of the patients in one systematic review containing 11 studies with 110 patients. $^{7-9}$ In line with this, recent studies suggest that $H$. pylori eradication therapy was even effective for patients without $H$. pylori infection. ${ }^{9-12}$ However, the majority of patients analyzed in those studies were at an early or localized stage of gastric MALT lymphoma, and most of these previous reports showed limited data with a small number of patients and insufficient staging work-up.

Recently, there have been reports suggesting that $H$. pylori infection has a relevant role even in high-grade B-cell lymphoma, and show CR after $H$. pylori eradication therapy. ${ }^{13,14}$ We, therefore, investigated the effectiveness of $H$. pylori eradica-

Correspondence to: Hwoon-Yong Jung

Department of Gastroenterology, Asan Medical Center, Asan Digestive Disease Research Institute, University of Ulsan College of Medicine, 88 Olympic-ro 43-gil, Songpa-gu, Seoul 05505, Korea

Tel: +82-2-3010-3197, Fax: +82-2-476-0824, E-mail: hyjung@amc.seoul.kr

Received on October 8, 2015. Revised on November 20, 2015. Accepted on November 23, 2015. Published online April 28, 2016

pISSN 1976-2283 eISSN 2005-1212 http://dx.doi.org/10.5009/gnl15510

Eun Jeong Gong and Ji Yong Ahn contributed equally to this work as first authors.

@ This is an Open Access article distributed under the terms of the Creative Commons Attribution Non-Commercial License (http://creativecommons.org/licenses/by-nc/4.0) which permits unrestricted non-commercial use, distribution, and reproduction in any medium, provided the original work is properly cited. 
tion therapy as the first-line treatment modality in all stages of MALT lymphoma, regardless of the $H$. pylori infection status in patients who finished all of the staging work-up.

\section{MATERIALS AND METHODS}

\section{Patients}

From November 1995 to September 2014, subjects who were diagnosed with gastric MALT lymphoma, who finished all of the staging work-up, and who underwent only $H$. pylori eradication therapy as the first-line treatment were eligible for this study. Their medical records were retrospectively reviewed. During the study period, a total of 694 patients were diagnosed with gastric MALT lymphoma. Among them, those who had other malignancies $(n=33)$, who had a previous history of treatment for MALT lymphoma $(n=84)$ or who underwent treatment other than $H$. pylori eradication therapy $(\mathrm{n}=80)$, including radiation therapy, resection or chemotherapy were also not eligible for inclusion in our study. Patients who did not complete the staging work-up $(n=100)$ or who were lost to follow-up $(n=102)$ were also excluded (Fig. 1). Finally, 345 patients were included in the analyses.

\section{Diagnosis and staging procedures}

The initial diagnosis of gastric MALT lymphoma was made on endoscopic examination and on histological assessment of gastric biopsies. The $H$. pylori infection status was determined by histology, a urea breath test, a rapid urease test, or serologic test. $H$. pylori infection was regarded as positive when at least one of those tests showed positive results and as negative only when all of the test results were negative. The result of eradication therapy was determined using histology, a urea breath test or a rapid urease test.

The location of the dominant lesion was grouped as the upper third, middle third or lower third of the stomach. Macroscopic findings were classified as the superficial, ulcerative or mass forming type based on the endoscopic appearance. The clinical stage was determined based on the Ann Arbor staging system with its modifications by Musshoff and Radaszkiewicz. ${ }^{5}$ The staging work up included physical examination, computed tomography scans of the chest, abdomen, and pelvis, endoscopic ultrasonography (EUS), and bone marrow aspiration and biopsy. ${ }^{5,6,15}$ Only the subset of patients who finished all of staging work up, including the EUS, were included in the final analysis in order to clarify the clinical stages and analyze the possible effect of the depth of invasion or clinical stage on the treatment outcomes.

\section{H. pylori eradication therapy}

All patients underwent $H$. pylori eradication therapy as the first-line treatment. The treatment regimen was chosen by the attending physician according to the medical history of each patient. Most patients received proton pump inhibitor (PPI)based triple therapy consisting of PPI (standard dose twice a day), clarithromycin (500 mg twice a day), and amoxicillin (1 g twice a day) for 7 to 14 days. When the patient had a previous history of $H$. pylori eradication therapy or the triple therapy had failed, PPI (standard dose twice a day), bismuth (300 mg 4 times a day), metronidazole (500 $\mathrm{mg} 3$ times a day), and tetracycline (500 mg 4 times a day) were used for 14 days.

\section{Follow-up and assessment of the treatment response}

Follow-up endoscopy with biopsies was performed 6 months after $H$. pylori eradication therapy, and periodic endoscopy followed every 3 to 6 months thereafter. Treatment response was defined according to the histological grading system proposed by the Groupe d'Etude des Lymphomes de l'Adulte (GELA), and being classified as either complete histological response (ChR), probable minimal residual disease (pMRD), responding residual disease (rRD), or no change (NC). ${ }^{5,16} \mathrm{CR}$ was defined as normal-

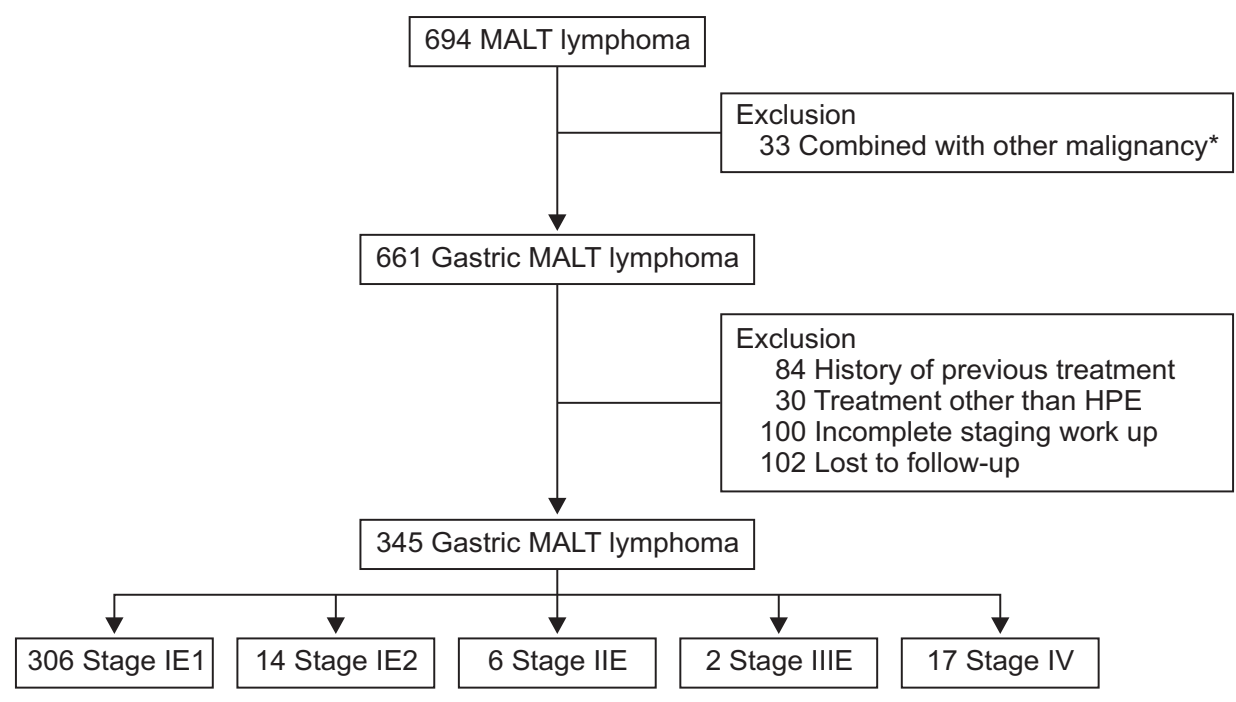

Fig. 1. Flowchart of this study. MALT, mucosa-associated lymphoid tissue; HPE, Helicobacter pylori eradication therapy. ${ }^{*}$ Combined with other malignances, including 12 gastric cancers, four colorectal cancers, three hepatocellular carcinomas, three papillary thyroid carcinomas, three lung cancers, three lymphomas, one cervical cancer, one neuroendocrine tumor, one esophageal cancer, one liposarcoma, and one metastatic adenocarcinoma with peritoneal seeding. 
ization of the endoscopic findings and negative biopsy results (ChR or pMRD) in two, subsequent follow-up biopsies. Partial response (PR) was defined as improved macroscopic findings with histologic signs of lymphoma regression (rRD). Stable disease (SD) was defined by unchanged endoscopic findings and/or unmodified histology (NC). Progressive disease (PD) was defined by worsening of the macroscopic findings, dissemination of the gastric MALT lymphoma or transformation into malignant lymphoma. Relapse was defined as the re-occurrence of histologically confirmed lymphoma after CR was previously documented.

Patients who failed to achieve CR after the eradication therapy underwent either careful observation or various additional treatments including radiation therapy, chemotherapy or surgical resection. Treatment failure was defined as when a patient did not achieve CR during the study period regardless of the degree of treatment response.

\section{Statistical analysis}

Continuous and categorical variables are presented as medians (range) and numbers (\%), respectively. Differences in the clinical characteristics were determined using the Student t-test, Mann-Whitney U test, Kruskal-Wallis test, chi-square test or Fisher exact test, as appropriate. Factors associated with remission failure were assessed using the logistic regression model, and the odds ratios (ORs) and corresponding 95\% confidence intervals were calculated. The time required to achieve CR or relapse was estimated and compared using the Kaplan-Meier method. The annual relapse rate was calculated as total number of relapse/cumulative observation years for all patients. All statistical analyses were performed using SPSS software version 18.0 (SPSS Inc., Chicago, IL, USA), and a p-value $<0.05$ was considered statistically significant.

\section{RESULTS}

\section{Characteristics of patients with gastric MALT lymphoma}

A total of 345 patients were analyzed (Table 1). The median patient age at the time of diagnosis was 53 years (interquartile range [IQR], 45 to 60 years), and the male to female ratio was 0.77:1. H. pylori infection was detected in 317 patients (91.9\%). The most frequently involved location was the middle third of the stomach ( $n=147,42.6 \%)$, followed by the upper third $(n=110$, $31.9 \%)$, and lower third $(n=88,25.5 \%)$. According to the disease stage, $92.8 \%(n=320)$ were diagnosed as stage IE. Two patients $(0.6 \%)$ were classified as having stage IIIE disease because of the lymphoma involvement of subcarinal and cervical lymph nodes, respectively. There were 17 patients (4.9\%) with stage IV disease, including 14 patients (4.7\%) with bone marrow involvement, two patients with lung involvement, and one patient with

Table 1. Clinical Characteristics of the Patients with Gastric MALT Lymphoma

\begin{tabular}{|c|c|c|c|c|}
\hline & Total $(n=345)$ & H. pylori-positive $(\mathrm{n}=317)$ & H. pylori-negative $(\mathrm{n}=28)$ & p-value \\
\hline Age, yr & $53(45-60)$ & $53(45-60)$ & $52(48-59)$ & 0.803 \\
\hline Male sex & $150(43.5)$ & $137(43.2)$ & $13(46.4)$ & 0.743 \\
\hline Location & & & & 0.005 \\
\hline Upper third & $110(31.9)$ & $98(30.9)$ & $12(42.9)$ & \\
\hline Middle third & $147(42.6)$ & $131(41.3)$ & $16(57.1)$ & \\
\hline Lower third & 88 (25.5) & $88(27.8)$ & 0 & \\
\hline Macroscopic findings & & & & 0.691 \\
\hline Superficial & $257(74.5)$ & $237(74.8)$ & $20(71.4)$ & \\
\hline Ulcerative & $83(24.1)$ & 75 (23.7) & $8(28.6)$ & \\
\hline Mass forming & $5(1.4)$ & $5(1.6)$ & 0 & \\
\hline Depth of invasion & & & & 0.893 \\
\hline Mucosa & $220(63.8)$ & $203(64.0)$ & $17(60.7)$ & \\
\hline Submucosa & $110(31.9)$ & $100(31.5)$ & $10(35.7)$ & \\
\hline Proper muscle & $15(4.3)$ & $14(4.4)$ & $1(3.6)$ & \\
\hline Stage & & & & 0.587 \\
\hline IE1 & $306(88.7)$ & $282(89.0)$ & $24(85.7)$ & \\
\hline IE2 & $14(4.1)$ & $13(4.1)$ & $1(3.6)$ & \\
\hline IIE & $6(1.7)$ & $6(1.9)$ & 0 & \\
\hline IIIE & $2(0.6)$ & $2(0.6)$ & 0 & \\
\hline IV & $17(4.9)$ & $14(4.4)$ & $3(10.7)$ & \\
\hline
\end{tabular}

Data are presented as median (interquartile range) or number (\%). MALT, mucosa-associated lymphoid tissue; Helicobacter pylori, H. pylori. 
small bowel and colon involvement.

\section{Treatment outcomes after $\boldsymbol{H}$. pylori eradication therapy}

The treatment outcomes of patients with gastric MALT lymphoma after $H$. pylori eradication therapy, according to the $H$. pylori infection status, are summarized in Table 2 and Fig. 2. $H$. pylori eradication was successful in $86.4 \%$ (274/317) of the patients with $H$. pylori infection. After eradication therapy, CR was achieved in a total of 284 patients (82.3\%), and the median time to CR after eradication therapy was 9.9 months (IQR, 7.2 to 15.6 months). Regarding the $H$. pylori infection status, the CR rate after eradication therapy was significantly higher in patients with $H$. pylori infection than in $H$. pylori-negative patients (84.5\% vs $57.1 \%, p=0.001$ ) (Table 2). Compared with H. pylori-negative patients, the median time to CR was shorter (9.8 months vs 11.5 months, $\mathrm{p}=0.455$ ) for $H$. pylori-positive patients.
Treatment outcomes and clinical courses according to the stage are shown in Table 3 and Supplementary Fig. 1. When comparing the $\mathrm{CR}$ rates after eradication therapy, there were no statistically significant differences among the stages, with a CR rate of $83.3 \%$ for stage IE1 and $74.4 \%$ for stage IE2 or above $(\mathrm{p}=0.167)$.

Among the 61 patients who failed to achieve CR after $H$. pylori eradication therapy, 19 received additional treatment including radiation therapy $(n=17)$, chemotherapy $(n=1)$, and surgical resection $(n=1)$. Of these 19 patients, 17 achieved CR after their additional treatment, and the total CR rate was $87.2 \%$ (301/345). The remaining 42 patients underwent a watch-andwait strategy and most of them (40/42) remained stable (PR or SD), while only two patients experienced PD (Fig. 2 and Supplementary Fig. 1). The time required to achieve CR and the time to relapse after CR in patients with gastric MALT lymphoma is

Table 2. Treatment Outcomes of Patients with Gastric MALT Lymphoma according to Helicobacter pylori Infection Status

\begin{tabular}{lcccc}
\hline & Total $(\mathrm{n}=345)$ & H. pylori-positive $(\mathrm{n}=317)$ & H. pylori-negative $(\mathrm{n}=28)$ & $\mathrm{p}$-value \\
\hline CR after HPE & $284(82.3)$ & $268(84.5)$ & $16(57.1)$ & $21(75.0)$ \\
$\mathrm{CR}^{*}$ & $301(87.2)$ & $280(88.3)$ & $11.5(10.0-22.3)$ & 0.001 \\
Time to CR, mo & $9.9(7.2-15.6)$ & $9.8(7.1-15.6)$ & $2(9.5)$ & 0.068 \\
Relapse & $32(10.6)$ & $30(10.7)$ & $8.1(5.7-10.6)$ & 0.106 \\
Time to relapse, mo & $11.5(6.2-16.8)$ & $11.5(6.3-21.0)$ & $2(100.0)$ & $\mathrm{NA}$ \\
CR after relapse & $24 / 29^{\dagger}(82.8)$ & $22 / 27^{\dagger}(81.5)$ & $7(25.0)$ & 0.097 \\
Treatment failure & $49 / 342^{\dagger}(14.3)$ & $42 / 314^{\dagger}(13.4)$ & & 0.370 \\
\hline
\end{tabular}

Data are presented as number (\%) or median (range).

MALT, mucosa-associated lymphoid tissue; CR, complete remission; HPE, H. pylori eradication therapy; NA, not assessed.

${ }^{*}$ Overall CR rate after additional treatment; ${ }^{\dagger}$ Two patients have not yet undergone two of the follow-up endoscopies, and one patient was lost to follow-up.
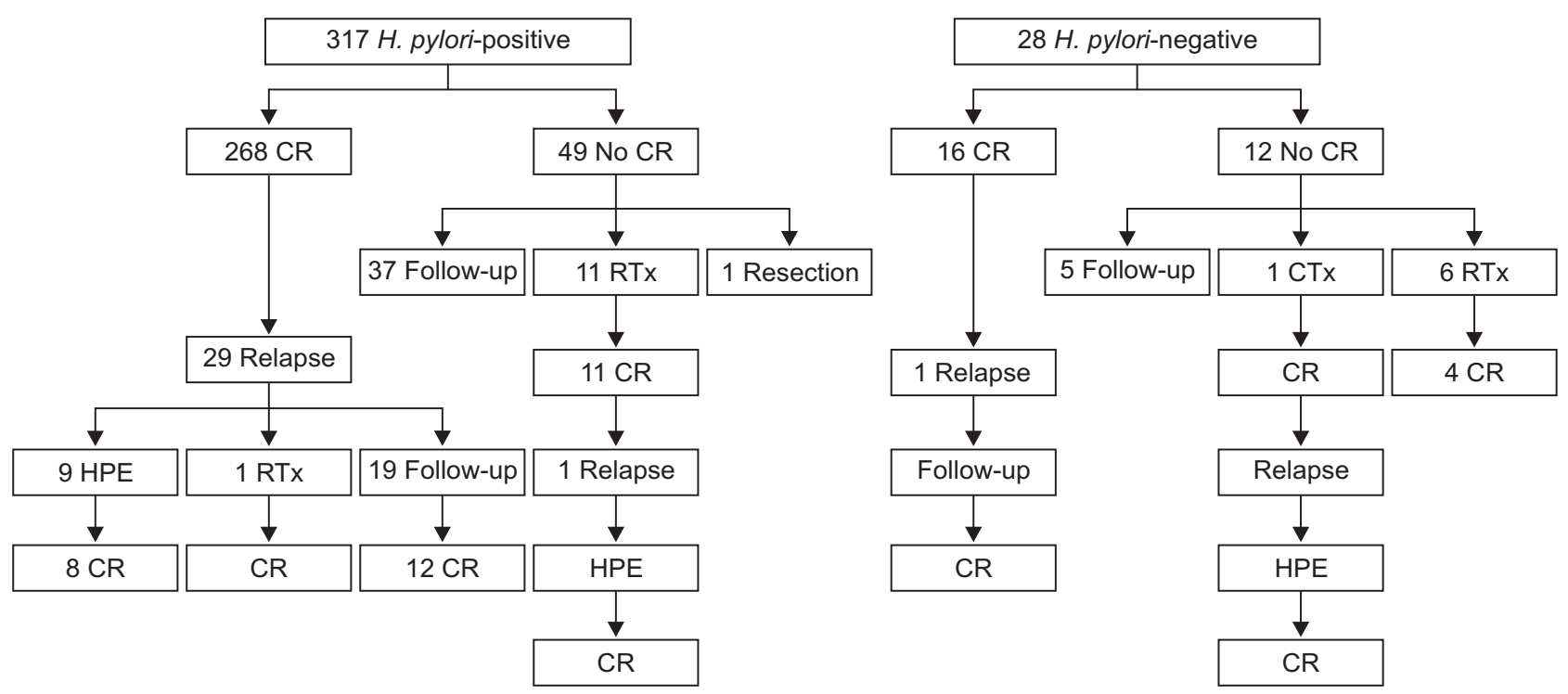

Fig. 2. Clinical course and treatment outcomes of patients with gastric mucosa-associated lymphoid tissue (MALT) lymphoma after Helicobacter pylori eradication therapy according to the $H$. pylori infection status.

CR, complete remission; RTx, radiation therapy; HPE, H. pylori eradication therapy; CTx, systemic chemotherapy. 
Table 3. Treatment Outcomes of Patients with Gastric MALT Lymphoma according to the Disease Stage

\begin{tabular}{|c|c|c|c|c|c|c|}
\hline & Stage IE1 $(n=306)$ & Stage IE2 $(n=14)$ & Stage IIE $(n=6)$ & Stage IIIE $(n=2)$ & Stage IV (n=17) & p-value \\
\hline CR after HPE & 255 (83.3) & $10(71.4)$ & $4(66.7)$ & $2(100.0)$ & 13 (76.5) & 0.396 \\
\hline $\mathrm{CR}^{*}$ & 267 (87.3) & $12(85.7)$ & $5(83.3)$ & $2(100.0)$ & $15(88.2)$ & 0.916 \\
\hline Time to $\mathrm{CR}$, mo & $9.9(7.2-15.1)$ & $10.1(5.7-17.1)$ & $7.2(6.2-9.4)$ & $16.4(10.6-22.2)$ & $15.2(8.1-20.1)$ & 0.493 \\
\hline Relapse & $28(10.5)$ & 1 (8.3) & 0 & 0 & $3(20.0)$ & 0.667 \\
\hline Time to relapse, mo & $10.5(6.2-16.4)$ & 14.7 & NA & NA & $13.0(10.0-29.5)$ & 0.479 \\
\hline $\mathrm{CR}$ after relapse & $21 / 25^{\dagger}(84.0)$ & $1(100.0)$ & NA & NA & $2(66.7)$ & NA \\
\hline Treatment failure & $43 / 303^{\dagger}(14.2)$ & $2(14.3)$ & 1 (16.7) & 0 & $3(17.6)$ & 0.930 \\
\hline
\end{tabular}

Data are presented as number (\%) or median (range).

MALT, mucosa-associated lymphoid tissue; CR, complete remission; HPE, H. pylori eradication therapy; NA, not assessed.

${ }^{*}$ Overall CR rate after additional treatment; ${ }^{\dagger}$ Two patients have not yet undergone two of the follow-up endoscopies, and one patient was lost to follow-up.

Table 4. Logistic Regression Analyses of the Factors Related to Complete Remission Failure

\begin{tabular}{|c|c|c|c|c|c|}
\hline & \multirow{2}{*}{$\begin{array}{c}\text { CR } \\
(n=301)\end{array}$} & \multirow{2}{*}{$\begin{array}{l}\text { No CR } \\
(\mathrm{n}=44)\end{array}$} & \multirow{2}{*}{ p-value } & \multicolumn{2}{|c|}{ Multivariable analysis } \\
\hline & & & & OR $(95 \% \mathrm{CI})$ & p-value \\
\hline Age, yr & $52(45-59)$ & $60(52-69)$ & $<0.001$ & $1.074(1.040-1.112)$ & $<0.001$ \\
\hline Male sex & $128(42.5)$ & $22(50.0)$ & 0.351 & - & - \\
\hline \multicolumn{6}{|l|}{ Location } \\
\hline Upper third & $93(30.9)$ & $17(38.6)$ & - & - & - \\
\hline Middle third & $125(41.5)$ & $22(50.0)$ & 0.914 & - & - \\
\hline Lower third & $83(27.6)$ & $5(11.4)$ & 0.037 & - & - \\
\hline \multicolumn{6}{|l|}{ Endoscopic appearance } \\
\hline Superficial & $220(73.1)$ & $37(84.1)$ & - & - & - \\
\hline Ulcerative & 77 (25.6) & $6(13.6)$ & 0.094 & - & - \\
\hline Mass-forming & $4(1.3)$ & $1(2.3)$ & 0.726 & - & - \\
\hline Depth of invasion (mucosa) & $192(63.8)$ & $28(63.6)$ & 0.967 & - & - \\
\hline Bone marrow involvement & $12(4.6)$ & $2(5.4)$ & 0.824 & - & - \\
\hline H. pylori infection & $280(93.0)$ & $37(84.1)$ & 0.049 & $0.366(0.144-1.018)$ & 0.041 \\
\hline
\end{tabular}

Data are presented as median (range) or number (\%).

$\mathrm{CR}$, complete remission; OR, odds ratio; CI, confidence interval; H. pylori, Helicobacter pylori.

shown in Table 3. The median time to CR did not show differences according to the $H$. pylori infection status and stages.

\section{Relapse after CR}

During the median follow-up period of 45.6 months (IQR, 23.9 to 72.0 months), relapse was detected in 32 of 301 patients (10.6\%) and the annual relapse rate was 2.4\% (Supplementary Fig. 2). The median time to relapse was 11.5 months (IQR, 6.2 to 16.8 months), and relapse was detected until 46.0 months following $\mathrm{CR}$. Compared with $H$. pylori-negative patients, the median time to relapse was longer (11.5 months vs 8.1 months, $\mathrm{p}=0.431$ ) for $H$. pylori-positive patients, although there was no statistically significant difference between the two groups.

Among 32 patients with relapse, 12 underwent additional treatment including repeated $H$. pylori eradication therapy and radiation therapy, and 17 patients were placed in a watch-and- wait status, and 82.8\% (24/29) achieved second CR. Two patients still have not undergone two follow-up endoscopies, and one patient was lost to follow-up. There were three patients with PD; one patient with $H$. pylori-positive gastric MALT lymphoma revealed transformation into diffuse large B cell lymphoma, and two of the $H$. pylori-negative patients developed transformation and dissemination of the MALT lymphoma. Finally, the overall treatment failure including primary remission failure or relapse after CR was 14.3\% (49/342), with $42 \mathrm{H}$. pylori-positive patients and seven $H$. pylori-negative patients. Regarding the disease stage, the treatment failure rates were $14.2 \%$ for stage IE1, $14.3 \%$ for stage IE2, $16.7 \%$ for stage II, and $17.6 \%$ for stage IV.

\section{Factors associated with remission failure}

Logistic regression analyses were performed to investigate the factors associated with remission failure (Table 4). Compared 
with the patients who did not achieve $\mathrm{CR}$, age, the location in the lower third of the stomach, and the $H$. pylori infection status were identified as risk factors for remission failure. Multivariate logistic regression analysis showed age $(0 R, 1.074 ; \mathrm{p}<0001)$ and $H$. pylori infection $(\mathrm{OR}, 0.366 ; \mathrm{p}=0.041)$ as factors related to the failure to achieve $\mathrm{CR}$.

\section{DISCUSSION}

In this study, we investigated the effectiveness of $H$. pylori eradication therapy as the first-line treatment of gastric MALT lymphoma, regardless of the $H$. pylori infection status and stages as well as the treatment outcomes. A total of 345 patients were analyzed, and $H$. pylori infection was detected in $91.9 \%$ of these patients. The $\mathrm{CR}$ rates after eradication therapy were $82.3 \%$ in total, $84.5 \%$ for $H$. pylori-positive patients and 57.1\% for $H$. pylori-negative patients, with the median time to CR of 9.9 months. The CR rates after eradication showed no significant difference according to the disease stages. These results suggest that eradication therapy is worthwhile, at least in some cases, in patients with $H$. pylori-negative MALT lymphoma as well as disseminated MALT lymphoma.

Gastric MALT lymphoma is a low-grade, indolent lymphoma showing favorable long-term outcomes. The causative role of $H$. pylori in the pathogenesis of gastric MALT lymphoma is well established, and the eradication of $H$. pylori leads to the $\mathrm{CR}$ of low-grade gastric MALT lymphoma in most patients. ${ }^{3,4,11,17-20}$ In contrast, patients without $H$. pylori infection and those with persisting lymphoma involvement following effective $H$. pylori eradication therapy are usually referred for oncologic treatment including chemotherapy and radiation therapy. Although the pathogenesis might differ in patients with $H$. pylori-negative gastric MALT lymphoma, there has been increasing evidence suggesting that eradication therapy can induce CR in some of these patients. ${ }^{7,9-12}$ That is, H. pylori eradication therapy can be used as the initial treatment in patients with gastric MALT lymphoma regardless of their $H$. pylori infection status. In our study, the CR rate was $57.1 \%$ for $H$. pylori-negative patients. Although CR rate was significantly lower than that of $H$. pyloripositive patients, eradication therapy induced CR in more than half of the patients with $H$. pylori-negative gastric MALT lymphoma, suggesting the role of $H$. pylori eradication therapy in selected patients.

To date, most studies which analyzed treatment outcomes are limited to early-stage or localized lymphoma. In this study, we included patients of all stages, and showed CR after $H$. pylori eradication as a sole therapy in $76.0 \%$ of the patients (19/25) with gastric MALT lymphoma of stage II or above. Moreover, neither the stage nor the presence of bone marrow involvement showed a statistically significant difference in patients who achieved CR and who were failed to achieve CR. Therefore, it seems reasonable to attempt eradication therapy before starting oncologic treatment which may be costly and potentially more toxic, independent of the disease stage.

Various predictive factors for CR have been reported, including the stage of the lymphoma, depth of invasion, the presence of the translocation $t(11 ; 18)(q 21 ; 21)$, and localization in the stomach. ${ }^{4,8121-23}$ In the present study, patient age and the $H$. pylori infection status were factors associated with $\mathrm{CR}$, which is concordant with a previous report including long-term followup data of 420 patients. $^{3}$ As the H. pylori infection status could result in a different treatment strategy and could affect the treatment outcome, accurate determination of the $H$. pylori status is necessary at time of the initial diagnosis. The proportion of $H$. pylori-positive patients among patients with gastric MALT lymphoma has been variously reported in different studies. The discrepancy in the rate of $H$. pylori infection may be partly explained by the geographic variation and the difference in the methods used to detect $H$. pylori infection. Indeed, the accuracy of the histopathologic examination may be affected by the sampling error or the degree of atrophic change of the gastric mucosa. In our study, $H$. pylori infection was detected in $91.9 \%$ of the patients, and which may reflect its high accuracy in diagnosing the $H$. pylori status.

Despite the fact than $H$. pylori eradication can induce CR in many patients, gastric MALT lymphoma may persist in nearly $20 \%$ of patients, and thus requiring further therapeutic approaches. Management should be individually tailored in these patients because delayed histological regression of MALT lymphoma after successful $H$. pylori eradication has been reported, even after a 24-month interval. ${ }^{6,19}$ In addition, minimal lymphoma residuals may persist at histological assessment without definite macroscopic lesions being detectable on endoscopy in some patients. In our study, 42 of 61 patients who failed to achieve $\mathrm{CR}$ with eradication therapy were placed in observation, and most (40/42) of these patients remained stable (PR or SD), while only two patients showed PD. Although there is no consensus regarding the period of observation necessary before making a decision of the treatment failure, it could be reasonable to withhold additional treatment for at least 12 months in the absence of clinical evidence of progression. ${ }^{3,5,17,18,20,23}$ Similarly, there has been no established consensus regarding the optimal followup duration after CR. In our study, relapse was detected even as long as 46.0 months after CR. Since MALT lymphoma recurrence is possible even years following $\mathrm{CR}$ and there is an elevated risk for gastric carcinoma in patients with MALT lymphoma, repeated endoscopic examinations with biopsies are warranted even after CR of gastric MALT lymphoma., 5,24,25

Our study has several limitations. First, being retrospective study conducted in a single referral center, a selection bias cannot be excluded. Indeed, the proportion of patients with localized stage disease was relatively lower in this study, and which may reflect a referral bias. We also included subjects who were fully evaluated prior to their treatment, including EUS examina- 
tion, which might lead to a bias. Subjects who were suspected of having extensive disease based on endoscopic examination or computed tomography scan might have not undergone EUS examination. Similarly, when endoscopic features and computed tomography scan suggest localized disease, eradication therapy might be performed without EUS or bone marrow examination. Therefore, the proportion of patients in each disease stage could not be representative of the real world situation. Second, the presence of translocation $\mathrm{t}(11 ; 18)(\mathrm{q} 21 ; \mathrm{q} 21)$, which is known to be a predictor of the treatment response of gastric MALT lymphoma, was not considered in this study. Despite these limitations, our study showed that patient age and $H$. pylori infection status were factors associated with $\mathrm{CR}$ in patients with gastric MALT lymphoma, with the large number of patients including all stages of gastric MALT lymphoma.

In conclusion, CR rate after eradication therapy was 82.3\% in total, with a relatively lower rate of $\mathrm{CR}$ in $H$. pylori-negative patients (57.1\%) than in the $H$. pylori-positive patients (84.5\%). However, $H$. pylori eradication therapy can be considered as the initial treatment for patients with $H$. pylori-negative gastric MALT lymphoma and even for patients with disseminated disease, before attempting aggressive, costly treatment.

\section{CONFLICTS OF INTEREST}

No potential conflict of interest relevant to this article was reported.

\section{ACKNOWLEDGEMENTS}

This work was supported by a grant from the Korean College of Helicobacter and Upper Gastrointestinal Research Foundation.

\section{REFERENCES}

1. Parsonnet J, Hansen S, Rodriguez L, et al. Helicobacter pylori infection and gastric lymphoma. N Engl J Med 1994;330:12671271.

2. Wotherspoon AC, Doglioni C, Diss TC, et al. Regression of primary low-grade B-cell gastric lymphoma of mucosa-associated lymphoid tissue type after eradication of Helicobacter pylori. Lancet 1993;342:575-577.

3. Nakamura S, Sugiyama T, Matsumoto T, et al. Long-term clinical outcome of gastric MALT lymphoma after eradication of Helicobacter pylori: a multicentre cohort follow-up study of 420 patients in Japan. Gut 2012;61:507-53.

4. Zullo A, Hassan C, Cristofari F, et al. Effects of Helicobacter pylori eradication on early stage gastric mucosa-associated lymphoid tissue lymphoma. Clin Gastroenterol Hepatol 2010;8:105-110.

5. Ruskoné-Fourmestraux A, Fischbach W, Aleman BM, et al. EGILS consensus report: gastric extranodal marginal zone B-cell lym- phoma of MALT. Gut 2011;60:747-758.

6. Dreyling M, Thieblemont C, Gallamini A, et al. ESMO Consensus conferences: guidelines on malignant lymphoma. Part 2: marginal zone lymphoma, mantle cell lymphoma, peripheral T-cell lymphoma. Ann Oncol 2013;24:857-877.

7. Raderer M, Streubel B, Wöhrer S, Häfner M, Chott A. Successful antibiotic treatment of Helicobacter pylori negative gastric mucosa associated lymphoid tissue lymphomas. Gut 2006;55:616-618.

8. Ruskoné-Fourmestraux A, Lavergne A, Aegerter PH, et al. Predictive factors for regression of gastric MALT lymphoma after antiHelicobacter pylori treatment. Gut 2001;48:297-303.

9. Zullo A, Hassan C, Ridola L, et al. Eradication therapy in Helicobacter pylori-negative, gastric low-grade mucosa-associated lymphoid tissue lymphoma patients: a systematic review. J Clin Gastroenterol 2013;47:824-827.

10. Ryu KD, Kim GH, Park SO, et al. Treatment outcome for gastric mucosa-associated lymphoid tissue lymphoma according to Helicobacter pylori infection status: a single-center experience. Gut Liver 2014;8:408-414.

11. Choi YJ, Kim N, Paik JH, et al. Characteristics of Helicobacter pylori-positive and Helicobacter pylori-negative gastric mucosaassociated lymphoid tissue lymphoma and their influence on clinical outcome. Helicobacter 2013;18:197-205.

12. Raderer M, Wöhrer S, Kiesewetter B, et al. Antibiotic treatment as sole management of Helicobacter pylori-negative gastric MALT lymphoma: a single center experience with prolonged follow-up. Ann Hematol 2015;94:969-973.

13. Cavanna L, Pagani R, Seghini P, Zangrandi A, Paties C. High grade B-cell gastric lymphoma with complete pathologic remission after eradication of Helicobacter pylori infection: report of a case and review of the literature. World J Surg Oncol 2008;6:35.

14. Montalban C, Santon A, Boixeda D, Bellas C. Regression of gastric high grade mucosa associated lymphoid tissue (MALT) lymphoma after Helicobacter pylori eradication. Gut 2001;49:584-587.

15. Zucca E, Copie-Bergman C, Ricardi U, et al. Gastric marginal zone lymphoma of MALT type: ESMO Clinical Practice Guidelines for diagnosis, treatment and follow-up. Ann Oncol 2013;24 Suppl 6:vi144-vi148.

16. Copie-Bergman C, Wotherspoon AC, Capella C, et al. Gela histological scoring system for post-treatment biopsies of patients with gastric MALT lymphoma is feasible and reliable in routine practice. Br J Haematol 2013;160:47-52.

17. Hong SS, Jung HY, Choi KD, et al. A prospective analysis of lowgrade gastric malt lymphoma after Helicobacter pylori eradication. Helicobacter 2006;11:569-573.

18. Wündisch T, Thiede C, Morgner A, et al. Long-term follow-up of gastric MALT lymphoma after Helicobacter pylori eradication. J Clin Oncol 2005;23:8018-8024.

19. Fischbach W, Goebeler-Kolve ME, Dragosics B, Greiner A, Stolte M. Long term outcome of patients with gastric marginal zone B cell lymphoma of mucosa associated lymphoid tissue (MALT) following exclusive Helicobacter pylori eradication therapy: experience 
from a large prospective series. Gut 2004;53:34-37.

20. Fischbach W, Goebeler ME, Ruskone-Fourmestraux A, et al. Most patients with minimal histological residuals of gastric MALT lymphoma after successful eradication of Helicobacter pylori can be managed safely by a watch and wait strategy: experience from a large international series. Gut 2007;56:1685-1687.

21. Choi YJ, Lee DH, Kim JY, et al. Low grade gastric mucosa-associated lymphoid tissue lymphoma: clinicopathological factors associated with helicobacter pylori eradication and tumor regression. Clin Endosc 2011;44:101-108.

22. Liu $\mathrm{H}$, Ye H, Ruskone-Fourmestraux A, et al. $\mathrm{T}(11 ; 18)$ is a marker for all stage gastric MALT lymphomas that will not respond to $\mathrm{H}$. pylori eradication. Gastroenterology 2002;122:1286-1294.

23. Stathis A, Chini C, Bertoni F, et al. Long-term outcome following Helicobacter pylori eradication in a retrospective study of 105 patients with localized gastric marginal zone B-cell lymphoma of MALT type. Ann Oncol 2009;20:1086-1093.

24. Raderer M, Streubel B, Woehrer S, et al. High relapse rate in patients with MALT lymphoma warrants lifelong follow-up. Clin Cancer Res 2005;11:3349-3352.

25. Copie-Bergman C, Locher C, Levy M, et al. Metachronous gastric MALT lymphoma and early gastric cancer: is residual lymphoma a risk factor for the development of gastric carcinoma? Ann Oncol 2005;16:1232-1236. 